flora $^{19}$ and isolation to prevent the acquisition of exogenous organisms ${ }^{20}$ should substantially reduce the risk of infection in neutropenic patients with leukaemia who are receiving cytotoxic drugs. Uncontrolled ${ }^{21}$ and controlled ${ }^{22}$ studies of protected environments and prophylactic antibiotics in patients with acute leukaemia have shown fewer infective episodes and fewer deaths from infection. Although it was considered that patients so protected could tolerate unusually intensive chemotherapy ${ }^{21}$ an increased remission rate was not observed, despite the reduction in deaths from infection..$^{22}$ In the controlled study the antileukaemic chemotherapy administered to the isolated patients was identical to that received by the control patientsthat is, no advantage was taken of their protected situation by using exceptionally aggressive therapy. Had this been done a higher remission rate might have been observed, although our own experience suggests that this is by no means certain.

In our small and deliberately heterogeneous group of patients, most of whom were selected because of their poor prognosis, the results of the antileukaemic treatment cannot be evaluated. The decontamination and isolation procedures, however, were highly effective, suppressing endogenous pathogens and completely preventing the acquisition of contaminants from the environment. Although we have not shown that such protection can substantially improve the outcome of antileukaemic chemotherapy it is extremely unlikely to make it worse. Extensive studies of intensive chemotherapy in protected environments are required to establish whether improved remission rates can be achieved.

The isolator system proved acceptable to patients, nurses, and medical staff. It is much cheaper than systems that depend on the construction of special rooms, and it can be rapidly dismantled and stored and is easily portable. Plastic isolators may be used in open wards without prejudicing their bacteriological security. Their use on open wards is desirable, since most patients become depressed when nursed for prolonged periods in single rooms, with or without a plastic isolator. Provision of sterile nursing suites based on the use of special rooms is not feasible below a certain size-four such rooms is probably the minimum-but it is easy to operate a single plastic isolator, securing better microbiological protection at much smaller financial outlay. And plastic isolators can be made available in small hospitals as well as in major centres.

\section{References}

1 Gordon, H A, and Pesti, L, Bacteriological Reviews, 1971, 35, 390.

2 Trexler, P C, Veterinary Record, 1971, 88, 15.

3 Drummond, A J, et al, Veterinary Record, 1973, 92, 555.

${ }^{4}$ Levenson, S M, et al, American fournal of Surgery, 1964, 107, 710.

${ }^{5}$ Haynes, B W, and Hench, M E, Annals of Surgery, 1965, 162, 641.

${ }^{6}$ Robertson, A C, et al, Lancet, 1968, 2, 1376.

7 Dietrich, M, et al, Revue Européenne d'Etudes Cliniques et Biologiques, $1972,17,488$.

${ }^{8}$ Wilson, R, et al, Germfree Research, p 37. New York, Academic Press, 1973.

9 Shadomy, S, et al, Archives of Environmental Health, 1965, 11, 183.

10 Penland, W Z, and Perry, S. Lancet, 1970, 1, 174.

11 Hummel, R P, et al, Annals of Surgery, 1972, 176, 742.

12 van de Waaij, D, et al, Germfree Research, p 31. New York, Academic Press, 1973.

13 Spiers, A S D, and Trexler, P C, fournal of Physiology, 1973, 231, 66P.

14 Trexler, P C, and Reynolds, L I, Applied Microbiology, 1957, 5, 406.

15 Sacquet, E, The Germ-Free Animal in Research, p. 1. New York, Academic Press, 1968.

${ }^{16}$ Gompertz, D, et al, Gut, 1973, 14, 183.

17 Spiers, A S D, British Medical fournal, 1973, 3, 528.

18 Spiers, A S D, et al, Lancet, 1975, 1, 829.

19 Preisler, H D, Goldstein, I M, and Henderson, E S, Cancer, 1970, 26, 1076.

20 Jameson, B, et al, Lancet, 1971, 1, 1034.

21 Bodey, G P, et al, Cancer, 1968, 22, 1018

22 Levine, A S, et al, New England fournal of Medicine, 1973, 288, 477.

\title{
Value of Doppler ultrasound in diagnosis of clinically suspected deep vein thrombosis
}

\author{
JEANETTE MEADWAY, A N NICOLAIDES, C J WALKER, J D O'CONNELL
}

British Medical fournal, 1975, 4, 552-554

\section{Summary}

Doppler ultrasound was used to study 120 legs of 106 patients with suspected deep vein thrombosis (DVT) or pulmonary embolism. Venography was subsequently performed in all. DVT was confirmed by venography in 44 legs and was confined to the calf in 10 of these. Ultrasound detected three calf thromboses and 29 out of 34 more extensive thromboses. Of five undetected thrombi that were proximal to the calf one was associated with partial

Waller Cardiopulmonary Unit, St Mary's Hospital, London W2 JEANETTE MEADWAY, MB, MRCP, senior research registrar

Blood Flow Laboratory and Surgical Unit, St Mary's Hospital Medical School, London W2

A N NICOLAIDES, MB, FRCs, lecturer in surgery

C J WALKER, MB, FRCS, senior registrar (locum) in orthopaedic surgery (now senior orthopaedic registrar, St Mary's Hospital, London W9)

Department of Radiology, St Mary's Hospital, London W2

J D O'CONNELL, MB, DMRD, FRCR, senior registrar (now consultant radiologist, St Finbarr's Hospital, Cork, Eire) occlusion and four with extensive collateral circulation. Of the 76 limbs without venographic evidence of thrombosis 21 were thought to have DVT by ultrasound; 18 of these false-positive results could be attributed to external compression of veins, two to excessive tenderness precluding adequate examination; and in one no explanation was found. This test gives more accurate results than judging by clinical signs alone, but users must be aware of its limitations and, particularly, the causes of falsepositive and false-negative results.

\section{Introduction}

The clinical diagnosis of deep vein thrombosis (DVT) is inaccurate. Half the thrombi in the calf do not produce signs, ${ }^{1-4}$ and $40 \%$ of patients with signs have normal veins on venography. ${ }^{56}$ Most clinical pulmonary emboli arise from veins proximal to the knee, ${ }^{7-9}$ and only small silent emboli arise from the calf. ${ }^{10}$ Early detection of thrombi in deep veins, particularly those extending into the popliteal and more proximal veins, is therefore essential for the prevention of pulmonary embolism. Some workers have claimed that Doppler ultrasound techniques may detect thrombi early, ${ }^{11}{ }^{12}$ both in routine screening ${ }^{13}{ }^{14}$ and in patients with clinical signs suggestive of venous thrombosis, ${ }^{15}$ but others have questioned its value. ${ }^{16}$ 
The purpose of this study was to assess the value of Doppler ultrasound in patients who presented with clinical signs of DVT or pulmonary embolism.

\section{Patients and methods}

Altogether 103 patients ( 120 limbs) were studied by both ascending venography and Doppler ultrasound. Ninety-four presented with a clinical diagnosis of DVT and nine with a clinical diagnosis of pulmonary embolism. Doppler ultrasound was performed before venography or with the examiner unaware of the venographic findings. The results of the Doppler ultrasound examination were compared with the venographic diagnosis.

Ascending venography-The technique used provided visualisation of the deep vein system from the calf to the inferior vena cava. ${ }^{6}$ Pneumatic cuffs were placed at the ankle and mid-thigh. Meglumine lothalamate $60 \%, \mathrm{w} / \mathrm{v}$ (Conray 280) was injected into a vein on the dorsum of the foot and directed into the deep veins by a cuff at the ankle. The passage of contrast medium into the deep veins was observed on an image intensifier and films were taken of the calf and knee regions. The thigh cuff was then deflated, the injection continued, and films were taken of the femoral and external iliac veins and inferior vena cava. If a filling defect was observed or suspected at least two films were taken. On average $80 \mathrm{ml}$ of contrast medium was injected. Finally, the cuffs were removed and the veins cleared of contrast medium by leg elevation and the injection of $150 \mathrm{ml}$ of normal saline containing 2500 units of heparin. Thrombosis was diagnosed when a constant filling defect was seen on at least two films. Non-visualisation of a vein was not considered diagnostic of thrombosis unless there was good opacification proximally and distally with the presence of a collateral circulation. ${ }^{17}$

Doppler ultrasound examination-This was performed with the patient in the semi-recumbent position (30 degrees) with the legs horizontal, using the Parks 801 ultrasonic blood flow detector. Initially the femoral artery was located, and then the probe was moved medially to detect the signal from the common femoral ve:n. The change in the signal was noted on respiration, Valsalva manoeuvre, manual compression of the thigh, and manual compression of the calf before and after occlusion of the long saphenous vein at the knee. The patient subsequently lay prone with head and shoulders raised and knees slightly flexed $\left(10^{\circ}\right.$ to $\left.15^{\circ}\right)$, resting the feet on a pillow. The probe was placed on the popliteal artery and vein. Firm pressure was used to occlude superficial veins. The efect on the signal of respiration and compression of the calf was again noted. A fiow signal at the groin which was low pitched, phasic with respiration, and abolished during a Valsalva manoeuvre was considered to be normal. Absence of this signal indicated an occluded external iliac vein. A high-pitched continuous signal at several positions medial to the artery, not affected by respiration and not abolished by a Valsalva manoeuvre, indicated the presence of a collateral circulation. Absence of augmentation of the signal on compression of the thigh indicated occlusion of the femoral vein. Absence of augmentation on compression of the calf with simultaneous occlusion of the long saphenous vein at the knee indicated occlusion of the popliteal vein. Changes in the popliteal signal with respiration and calf compression provided a double check on the patency of this vein.

\section{Results}

Of 120 limbs studied venography showed a deep venous system without any evidence of thrombosis in 76 . The Doppler findings were normal in 55 of the limbs with normal veins, but suggested occlusion in 21 . In the latter group 11 limbs had oedema, four had haematomas, and one a lymphocyst compressing the veins; one had cellulitis and one an injured muscle. Extreme tenderness in two limbs (one patient) precluded adequate calf compression, and no cause was found in one limb.

Venography showed thrombi in 44 limbs. In 10 the thrombus was confined to the calf and Doppler ultrasound detected three of these. Thirty-four thrombi extended into the popliteal and more proximal veins. Doppler ultrasound detected $29(85 \%)$ of them. Five $(15 \%)$ limbs with proximal thrombosis were normal on Doppler examination, and venograms showed a good collateral circulation in four and partial occlusion in one. Of the six thrombi that were extending just into the popliteal vein, five were detected by ultrasound.
No complications resulted from venography or ultrasound examination in any of the patients.

\section{Discussion}

The results of this study show that, although Doppler ultrasound is a relatively simple and safe test, it has certain limitations. In five of the 34 patients with thrombi proximal to the knee ultrasound did not detect any evidence of thrombosis, though it is in this region that the test is thought to be most accurate. The failure to detect partially occluding thrombi and thrombi in veins with a good collateral circulation is a serious drawback because it is from these veins that large pulmonary emboli arise. If too much reliance is placed on normal ultrasound results and venography is not performed such thrombi may remain untreated. The presence of a false-positive ultrasound finding, though not as dangerous as a false-negative result, is undesirable. Most of the false-positive findings were in clinically abnormal limbs and inappropriate anticoagulant treatment, which is expensive and has its dangers, might have been given if venography had not been carried out. Ultrasound cannot distinguish between external compression or thrombosis causing occlusion. Two of the four patients with haematoma were in fact treated with intravenous heparin infusion while awaiting venography, with consequent clinical deterioration.

Oedema was one of the main causes of false-positive ultrasound findings. This was probably the result of relatively little blood in the calf veins, which are compressed and collapsed. Calf compression during examination ejects relatively little blood into the popliteal and femoral veins and poor augmentation of the signal may be interpreted as the result of thrombosis. Our findings suggest that this test is extremely unreliable in the presence of oedema.

Overall the ultrasound examination was inaccurate in 33 out of 120 cases $(27.5 \%)$, and this is not just the well-known failure to detect minor calf thrombi. ${ }^{18}$ Nevertheless, its overall accuracy of $72.5 \%$ was better than that gained from clinical signs alone $(50 \%){ }^{4}{ }^{9}$ Altogether $85 \%$ of the dangerous thrombi that are proximal to the calf and are responsible for clinical pulmonary emboli ${ }^{7}$ can be detected.

The augmentation of the signal at the groin produced by calf compression was abolished by simultaneous occlusion of the long saphenous vein in five of the six limbs with thrombus extending just into the popliteal vein. This manoeuvre is essential for the detection of such thrombi.

The simplicity of ultrasound makes it a useful examination while the patient is awaiting venography, but it is important that users are aware of its limitations and, particularly, the causes of false-positive and false-negative results.

Because of its nature the test has a subjective element (correct positioning of the probe and interpretation of the signals improve with practice), and those of us who performed these ultrasound examinations had been using the technique for some years.

We thank the physicians and surgeons of St Mary's Hospital for allowing us to study their patients and Professor H A F Dudley and Dr P H Kidner for their advice.

\section{References}

1 Sevitt, S, and Gallagher, N G, British fournal of Surgery, 1961, 48, 475.

2 Flanc, C, Kakkar, V V, and Clarke, M B, British fournal of Surgery, 1968, 55,742 .

3 Negus, D, et al, British fournal of Surgery, 1968, 55, 835.

4 Nicolaides, A N, Jacksonian prize essay, 1972.

5 Haeger, K, Angiology, 1969, 20, 219.

${ }^{6}$ Nicolaides, A N, et al, British fournal of Radiology, 1971, 44, 653.

${ }^{7}$ Kakkar, V V, et al, Lancet, 1969, 2, 230.

8 Mavor, G E, and Galloway, J M D, British fournal of Surgery, 1969, 56, 45.

9 Kemble, J V H, British fournal of Hospital Medicine, 1971, 6, 721.

10 Browse, N L, Clemenson, G, and Croft, D N, British Medical fournal, $1974,1,603$. 
11 Strandness, D E, et al, American fournal of Surgery, 1967, 113, 311.

12. Sigel, B, et al, Surgery, 1968, 64, 332.

${ }^{13}$ Evans, D S, and Cockett, F B, British Medical fournal, 1969, 2, 802.

14 Sigel, B, et al, Archives of Surgery, 1972, 104, 174.

15 Strandness, D E, and Sumner, D S, Archives of Surgery, 1972, 104, 180.
${ }^{16}$ Murray, J G, and Kakkar, V V, in Scientific Basis of Surgery, ed W T Irvine, Edinburgh and London, Churchill Livingstone, 1972.

17 De Weese, J A, and Rogoff, S M, Surgery, 1963, 53, 99.

${ }^{18}$ Evans, D S, Annals of the Royal College of Surgeons of England, 1971, 49, 225

\title{
Laparoscopy and laparotomy combined with bone marrow biopsy in staging Hodgkin's disease
}

\author{
P SPINELLI, G BERETTA, E BAJETTA, G TANCINI, R CASTELLANI, F RILKE, \\ G BONADONNA
}

Since bias from retrospective comparative evaluations cannot be entirely eliminated, and the American series was preselected for more advanced disease, we decided to combine both laparotomy and laparoscopy in a series of untreated and treated patients with Hodgkin's disease to establish more clearly the relative merits of both staging procedures.

The relative merits of laparoscopy with liver and spleen biopsy and staging laparotomy were studied in 91 unselected patients with Hodgkin's disease. Laparoscopy with liver and spleen biopsy were combined with needle biopsy of the bone marrow and laparotomy was combined with open bone marrow biopsy. In 65 untreated patients six out of seven with liver or marrow disease, or both, were shown to have extranodal lymphomas in these sites by laparoscopy plus needle marrow biopsy. Among 26 patients who had been treated this finding occurred in six out of 10 patients. Spleen biopsies during laparoscopy detected infiltration by lymphoma in 14 out of $37\left(3^{\circ}{ }^{\circ}\right)$ patients with diseased spleens. Morbidity was higher after laparotomy than after laparoscopy. Laparoscopy produced abdominal bleeding secondary to splenic biopsy in two patients. All patients with Hodgkin's disease should be subjected to laparoscopy plus needle marrow biopsy before undergoing laparotomy.

\section{Introduction}

Accuracy in staging Hodgkin's disease has been improved recently by the use of laparotomy with splenectomy and multiple tissue biopsies, including open bone marrow biopsy. Though essentially devoid of major surgical complications laparotomy has not been accepted by all centres as a routine staging procedure for surgically low-risk patients with clinical stage I, II, and III disease.

In 1970 the National Cancer Institute group in the USA began to study the value of laparoscopy in detecting liver involvement in patients with untreated Hodgkin's disease. Their most recent results ${ }^{1}$ showed that hepatic disease in 47 untreated patients was shown with the same frequency by multiple liver biopsies as that reported by wedge biopsy at laparotomy. They concluded that laparoscopy could be an alternative to laparotomy in establishing stage IV disease.

Instituto Nationale Tumori, Milan, Italy

$P$ SPINELLI, MD, chief of endoscopy service

G BERETTA, MD, clinical assistant, division of clinical oncology $F$

E BAJETTA, $M D$, clinical assistant, division of clinical oncology $F$

G TANCINI, MD, clinical assistant, division of clinical oncology $\mathrm{F}$

$R$ CASTELLANI, MD, research fellow, division of clinical oncology $F$

$F$ RILKE, MD, associate director, division of pathology

G BONADONNA, ass sciate director, division of oncology $F$

\section{Patients and methods}

The study was carried out on 91 unselected patients aged 13-69 years who were admitted to the Instituto Nationale Tumori from 1 October 1973 to 31 March 1975. The patients fell into two groups: 65 patients had never been treated; and 26 patients had been treated and were either incompletely staged in other hospitals or relapsing from primary treatment.

Clinical diagnostic evaluation included routine haematological studies, chest $x$-ray examination, skeletal survey, and leg lymphography. Liver radionuclide scans were performed in 37 patients and spleen scans in 24 . Scans were usually performed when we thought that they could add further information to help us define the clinical stage more accurately. All patients were staged according to the clinical criteria proposed at Ann Arbor.

One to three days before laparoscopy a posterior iliac crest bone marrow biopsy was performed with Jamshidi needle. Laparoscopy was performed in all patients. Classic staging laparotomy with open iliac crest marrow biopsy was carried out in patients with negative histological findings in the liver on laparoscopy and the bone marrow on needle biopsy.

The Wolf cold light endoscope was used. The procedure was performed in the morning, after an overnight fast. The pneumoperitoneum was created by $2-3$ litres of carbon dioxide through the insertion of a Veress needle into the left lower quadrant of the abdomen. Under local lignocaine hydrochloride (Xylocaine) anaesthesia the laparoscopy trocar was inserted $1-2 \mathrm{~cm}$ above the umbilicus in the midline. To avoid intraperitoneal adhesions in patients who had undergone abdominal surgery through midline laparotomy the entry of the trocar was placed laterally on the right. Liver and spleen biopsies were performed with the Tru-cut needle (Travenol Laboratories). When abnormal areas were present a specimen was also taken from the liver edge with a Palmer forceps. The biopsy needle was introduced costal margin for liver biopsy and in the left ninth intercostal space at the intercept with the anterior axillary line for spleen biopsy. Only in seven patients was a single liver biopsy specimen obtained. In the remaining patients one or more specimens were obtained from each hepatic lobe ( 2 in 36 cases, 3 in 26, 4 in 15, 5 in 6, and 6 in 1). Splenic biopsies ( 1 in 46 patients, 2 in 29 , and 3 in 1 ) were usually obtained from the medial aspect of the lower pole without use of adrenaline. In patients with tumour nodules on the surface of the liver or spleen specimens were first obtained from abnormal areas. In most patients the procedure was completed within 20 minutes.

\section{Results}

Table I presents the findings of sequentially combined staging procedures in untreated patients. Specimens from the spleen could not $2 \mathrm{~cm}$ medially to the intercept of the right midclavicular line with the 